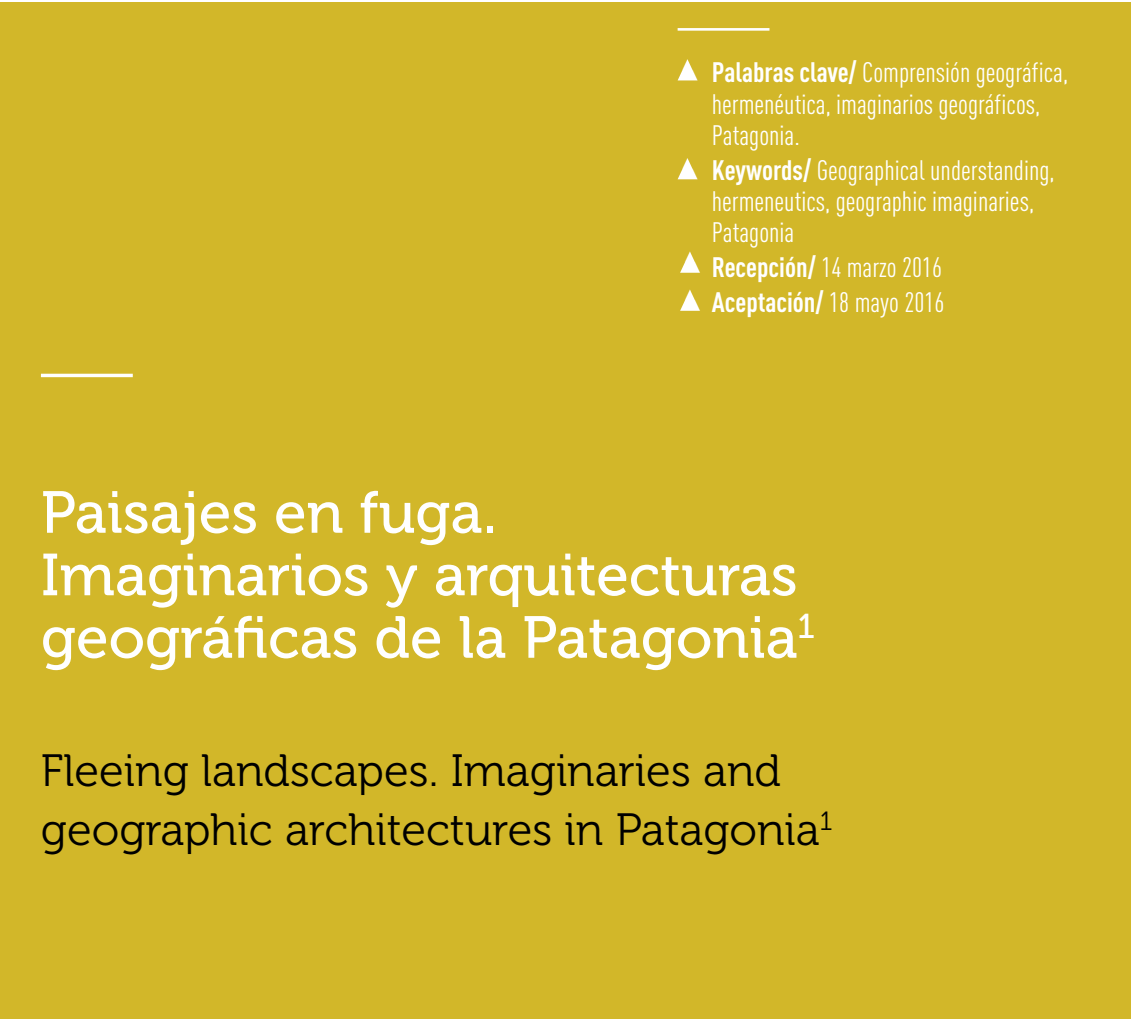

\author{
Andrés Núñez \\ Doctor en Historia, Pontificia Universidad \\ Católica de Chile, Chile. \\ Historiador, Instituto de Geografía, Pontificia \\ Universidad Católica de Chile, Chile. \\ aanunezg@uc.cl
}

\section{Enrique Aliste}

Doctor en Geografía y Estudios del Desarrollo, École des Hautes Études en Sciences Sociales (EHESS) de París, Francia.

Magíster en Gestión y Planificación Ambiental, Universidad de Chile, Chile.

Profesor en el Departamento de Geografía,

Universidad de Chile, Chile.

ealiste@uchilefau.cl

\section{Federico Arenas}

Doctor en Ciencias Económicas y Sociales,

Mención Geografía, Universidad de Ginebra,

Suiza. Geógrafo, Instituto de Geografía, Pontificia

Universidad Católica de Chile, Chile

farenasv@uc.cl

RESUMEN/ El texto propone la comprensión geográfica en el marco de las disciplinas hermenéuticas. En este contexto, resalta la constante producción de imaginarios geográficos respecto de la Patagonia. Se identifican verdaderas arquitecturas geográficas que, junto a su solidez, parecen estar en un inevitable tránsito, en una fuga cuya función central es la de rearmarse de memoria para comprenderse en un horizonte temporal que es, a su vez, cultural. Aquellas fugas -esas huidas u horizontes móviles- dan paso a nuevas arquitecturas que buscan afianzarse como sólidos edificios de la comprensión social, y aunque lo son, pronto darán paso a renovadas formas de interpretación que derivarán en nuevos paisajes, los cuales serán tanto materiales como sueños de una época, experiencias y existencias de un devenir. ABSTRACT/ The text suggests a geographic understanding in the context of hermeneutic disciplines. Against this backdrop, there is a constant production of geographic imaginaries regarding Patagonia. True geographic architectures are identified, which, in addition to their solid nature, seem to be inevitably in transit, fleeing, mainly to reshape their memory and to understand themselves in a time and -at the same time- cultural horizon. Such escapes -flights or moving horizons- give way to new architectures that aim at becoming strongholds for social understanding, and although they are, they will soon give way to renewed interpretations that shall derive in new landscapes, which will be both material and dreams of an epoch, experiences and existence of a progression.

INTRODUCCIÓN. Es muy común observar

una geografía asociada a una comprensión del espacio como objeto, es decir, a un espacio donde sujeto y objeto funcionan por separado. Es el sujeto el que se encarga de describir, localizar y mensurar lo que parecería estar 'allí afuera'. Desde esa perspectiva, en general, los estudios geográficos han invisibilizado el rol que juega el sujeto social en la configuración de aquellos espacios. A su vez, han colaborado en la minimización del espacio existencial, cuyo vínculo con la memoria y con el significado temporal es ineludible. Sin embargo, especialmente en las últimas décadas, se ha venido subrayando y revalorizando la interpretación de un sujeto social que no puede evadirse de la simbiosis que implica entender que lo geográfico es temporalidad y espacialidad a la vez. Es decir, que la comprensión geográfica tiene subsumida un modo de visualizar el tiempo y el espacio.

A la fecha, numerosos estudios geográficos (Harvey 2007; Lindon 2010; Nogué 2009; Soja 1996; Tuan 2007; Zusman et al 2011) 
han apuntado a otras perspectivas, donde la movilidad y cambio de la representación geográfica resaltan por su protagonismo. Así, lo que observamos vendría a ser una realidad en fuga, de paso, en tránsito, no definitiva, es decir, finita.

En este marco, el espacio y, a partir de él, el paisaje, no es un círculo cerrado, sino que es un desplegar (se): "El paisaje es una huida hacia toda la tierra, una ventana de posibilidades ilimitadas: un horizonte" (Dardel 2013: 91). En otras palabras, es el resultante de una interacción de la apropiación del sentido espacial: sujeto y objeto se funden en un 'horizonte efectual' donde el 'comprender' es, finalmente 'diálogo' (fusión de horizontes) entre la experiencia comprensiva (sujeto social) y la convivencia del horizonte histórico de la comprensión (objeto) ${ }^{2}$.

En esta línea de argumentación, el espacio geográfico deriva en un 'mundo' (que es comprensión y horizonte de la comprensión) o "cosmovisión" (Tuan 2007). Al respecto, Dardel (2013) expone:

"Cuando queremos reducir la geografía a un puro conocimiento objetivo, el elemento propiamente terrestre de la Tierra desaparece. Las nociones y las leyes que podemos extraer no conservan su valor más que si las arrancamos en un combate a algo que continúa escondiéndose, a una existencia animal. Es esta lucha incesante de la luz y de la oscuridad, del Hombre $y$ de la Tierra, la que confiere a cualquier construcción humana lo que tiene de concreto y de real y, de alguna manera, cualquier descubrimiento, cualquier "geografía", a la vez que es concesión a la Tierra, abandono a la fuente que nos hace ser, manifiesta nuestra historicidad fundamental" (2013: 102).
Así, por aquella relación existencial con la tierra, el espacio de 'lo geográfico' no podría ser únicamente materialidad sino fundamentalmente temporalidad/ historicidad. Aquí hay una modificación sustancial al enfocar la temática geográfica. Esta perspectiva invierte el enfoque tradicional de los estudios geográficos anclados en el marco de las ciencias empírico-analíticas para trasladarlos al de las disciplinas hermenéuticas (Aliste et al. 2015; Núñez 2013).

En este marco, nuestra investigación ha permitido observar la constante producción de imaginarios geográficos respecto de la Patagonia. Se trata de verdaderas arquitecturas que, junto a su solidez, parecen estar en un inevitable tránsito, en una fuga cuya función es rearmarse de memoria para comprenderse. Aquellas fugas, esas huidas u horizontes móviles, dan paso a nuevas arquitecturas que buscan afianzarse como sólidos edificios de la comprensión social y, aunque lo son, pronto darán paso a renovadas formas de interpretación que derivarán en nuevos paisajes, que serán tanto materiales como sueños de una época, existencias de un devenir. Como ha expuesto Canaparo (2011): "Lo que da sentido al espacio nunca es

\section{CONSTRUYENDO UNA GEOGRAFÍA \\ PATAGÓNICA. El diccionario de la Real}

Academia Española (2012) no posee registro para la palabra Patagonia. Es decir, de acuerdo a la fuente, no está asociada a un territorio específico. Sin embargo, sabemos que ella presenta asociaciones concretas, vínculos con espacios reales, aunque sus lecturas se asientan en imaginarios geográficos relacionados con el lente cultural desde donde se comprende. En
1880, por ejemplo, una visitante inglesa, Florence Dixie, explicaba que al momento de anunciar su viaje a la Patagonia, sus parientes habian exclamado: "iPatagonia! ¿Quién pensaría jamás en ir a un lugar así? Serás devorada por los caníbales. ¿Por qué razón escoges un lugar tan apartado del mundo para ir? ¿Cuál puede ser el atractivo? Está a miles de millas de distancia y nadie ha estado allí antes excepto el capitán Musters y uno o dos aventureros locos" (1996:17). En otras palabras, el concepto Patagonia evocaba lejanía, irracionalidad, riesgo e inseguridad.

En la actualidad, es probable que la reacción fuese diferente $y$, tal vez, aunque siguiese significando distancia, representaría a su vez asombro, fascinación y recogimiento. Frente a la negatividad de fines del siglo XIX, su proyección geográfica se hace de modo más amigable en el presente.

¿Qué es, entonces, Patagonia? Una respuesta a esta pregunta no es única ni definitiva. Es, por el contrario, múltiple, móvil y posee una fuerte carga de historicidad y memoria. Para definirla, entonces, consideraremos que Patagonia puede ser captada como un área de montaña o una pampa, pero ella se moviliza, en definitiva, entre una proyección de imágenes cargadas de valores y sentidos acorde a la época en que va siendo asimilada. Es decir, la impresión que nos hacemos de la Patagonia no está ligada necesariamente al objeto 'Patagonia' sino al hecho de que su proceso de significación es el resultado de imbricaciones y tejidos que la formulan (Bachelard 2010). La Patagonia es la multiplicidad de imágenes geográficas que ella evoca de acuerdo a la proyección cultural de los que la observan (Said 2002). Patagonia sería, por tanto, Patagonias, en plural.

${ }^{2}$ Nuestra propuesta considera como base los trabajos de Dardel 2013; Foucault 2010; Bachelard 2010; Tuan 2007; Heidegger 1997, entre otros, aunque el pilar fundamental de ella se asienta en la Hermenéutica Filosófica expuesta por Gadamer (1999) 


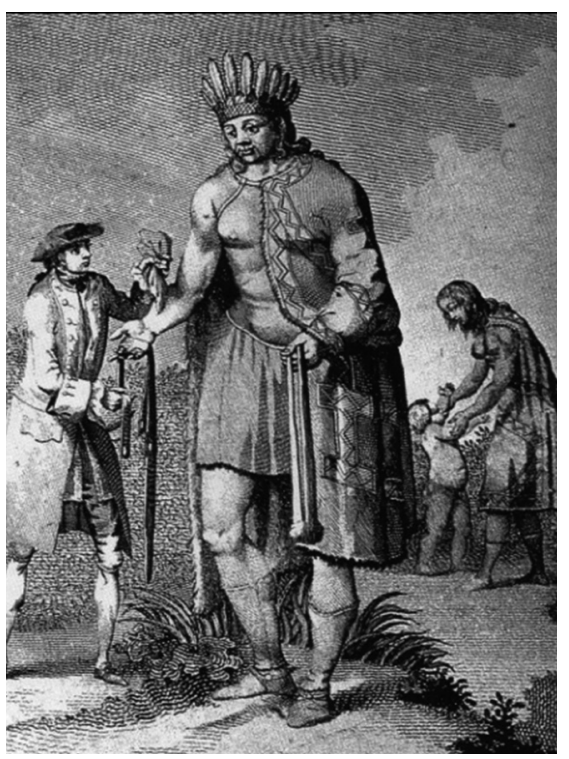

Imagen 1. Patagón gigante de las zonas australes. Grabado del siglo XVIII (fuente: Rojas 1992)
PAISAJES EN MOVIMIENTO, PAISAJES

EN FUGA. Patagonia fue un concepto

surgido desde el lente europeo y, en general, se asoció a un amplio territorio de la zona sur-austral del continente americano. Desde esta perspectiva, Patagonia fue en primer lugar una 'tierra sin historia', referida a un espacio de silencio aborigen?

En 1520, los Sélknam u Onas fueron avistados por los europeos, quienes proyectaron en los primeros dos características que marcarían el devenir posterior de la Patagonia: una 'tierra de

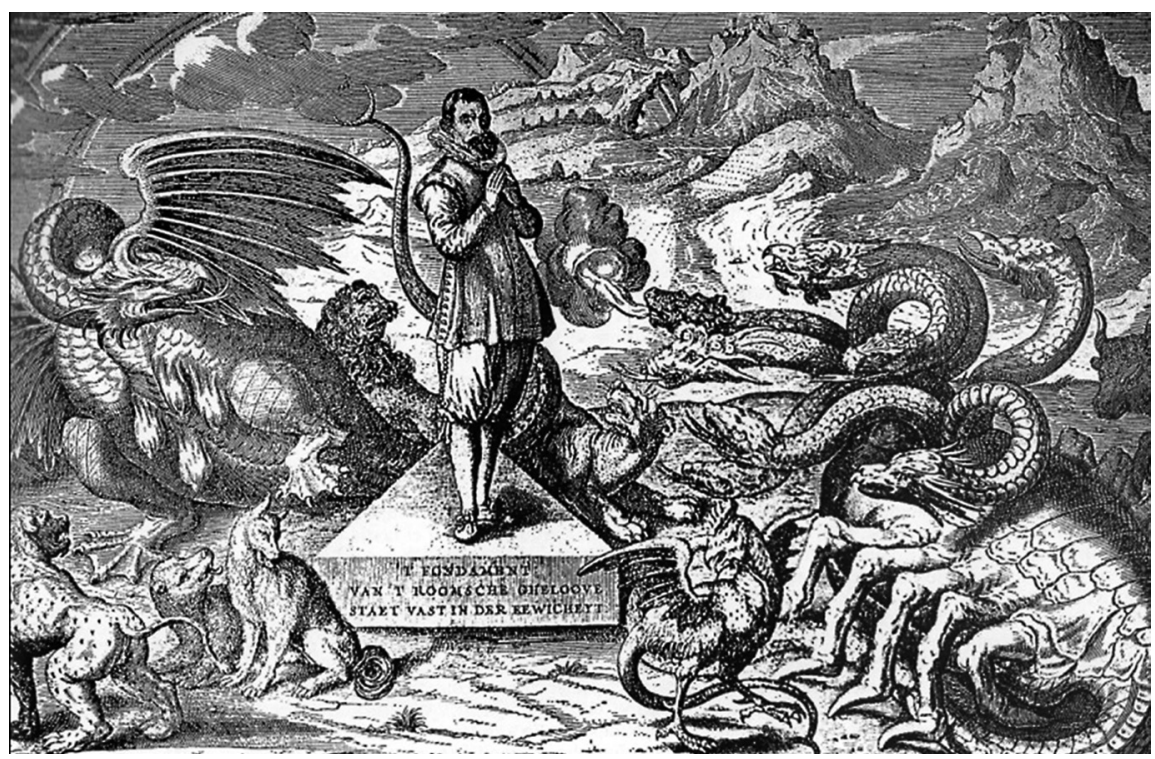

Imagen 2. Paisaje mitológico de la Patagonia del siglo XVI (fuente: Rojas 1992).

fuegos' y de 'gente grande' (imagen 1). Este atributo de 'pie grande' ha quedado tan arraigado que llegó incluso a monopolizar el significado de la palabra Patagonia. De hecho, el navegante Pigafetta relataba hacia 1520 que "un día, cuando menos lo esperábamos, un hombre de aspecto gigantesco se presentó ante nosotros... Era tan grande que nuestras cabezas apenas llegaban a su cintura... Hay muchísimos en esta tierra." (1999: 90). Esta descripción generó el mito.

Bajo el mismo sentido, el propio Hernando de Magallanes habría quedado impactado por la fisonomía de los indígenas que, con sus pieles gruesas, pelo largo y caras pintadas, le recordaban al 'Patagón', un monstruo con cabeza de perro del romance español del siglo XVI, Amadís de Gaula. Así, la frase "Patagonia, tierra maldita" fue acuñada por los viajeros que visitaban la zona (Ritchie Key 2002)

El topónimo Patagonia presenta una aparición temprana en el mapa de 1522 del cartógrafo imperial Alonso de Chaves, donde la zona austral se indica como "La tierra de los Patagones" (Muñoz 2009). Su nombre, si bien no fue masificado hasta las exploraciones científicas del siglo XVIII, comenzó a volverse un horizonte territorial reconocido como el fin del mundo en el contexto de las distintas expediciones que buscaban unir los dos océanos. Aquellas expediciones dieron origen a una representación que perduró durante muchas décadas: la Patagonia como paisaje mítico e inconmensurable (imagen 2).

Incluso hacia el ilustrado siglo XVIII, lo inexplicable era aún su naturaleza exuberante y territorio de seres extraños. Numerosos mapas y leyendas así lo refrendan. Una de ellas, tal vez la más conocida, es la Ciudad de Los Césares o

Ciudad Encantada de la Patagonia. Muchas expediciones en los siglos siguientes se internaron en la cordillera de Los Andes en su búsqueda y el paisaje mitológico retrató a la Patagonia.

Con una dominación europea más consolidada, en pleno siglo XVIII y XIX, la imagen de asombro de las tierras patagónicas derivó en un proceso de racionalización que homologó al indígena con lo salvaje o, precisamente, lo irracional. A ello se sumó el surgimiento de los Estados-nación, que colaboró en la identificación de particularidades nacionales

En este amplio contexto, comienza a afianzarse otra imagen geográfica cuyo arraigo también perdura hasta el presente, esto es, la Patagonia como 'desierto'. 


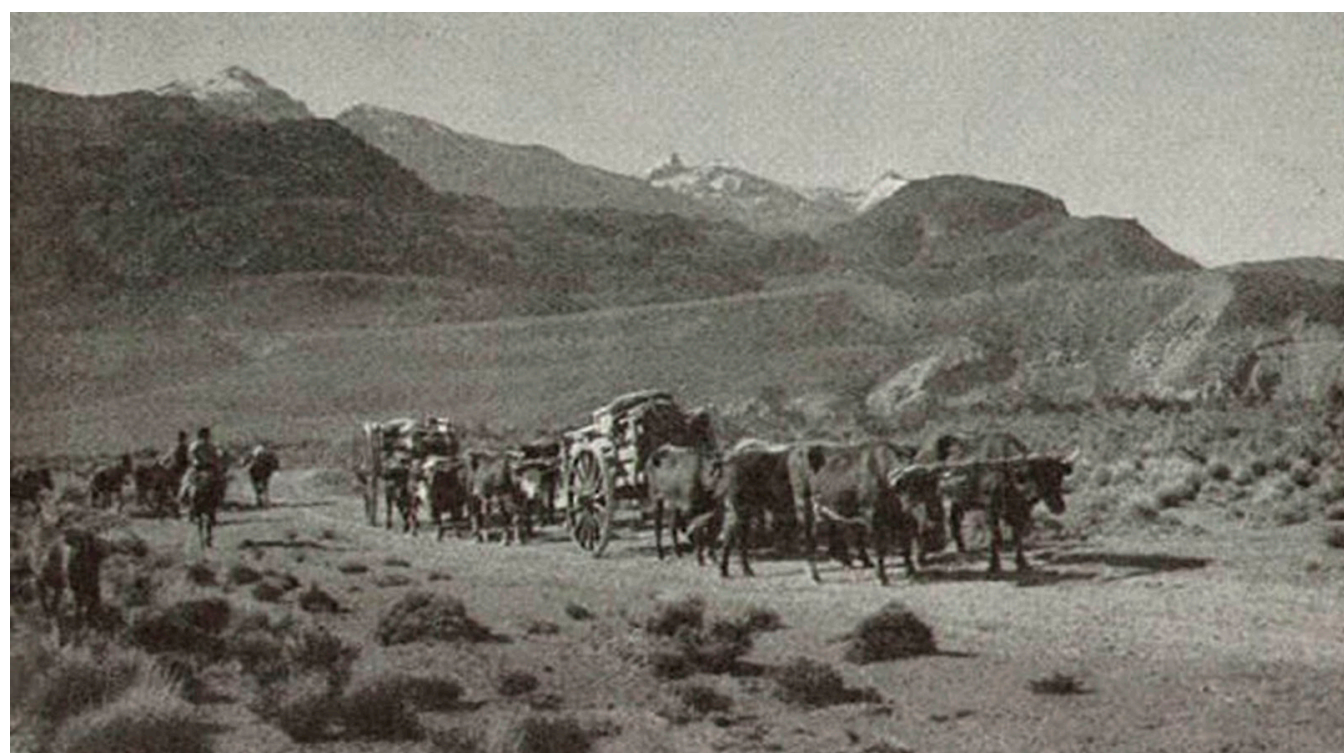

Imagen 3. Colonización espontánea de fines de/ siglo XIX y principios del XX. (fuente: Biblioteca Nacional).

emulando al viejo oeste americano. Este proceso se dio, en primer lugar, en la actual Argentina a fines del siglo XIX a partir de colonias de extranjeros de diversas nacionalidades, muchas de las cuales han dado fisonomía a diversos asentamientos que perduran hasta el día de hoy. Paralelamente, chilenos que vivían efectivamente en la zona norte de la Patagonia argentina, presionados por el Estado nacional, derivaron finalmente en valles cordilleranos contiguos a la pampa argentina. Estos migrantes fundaron los asentamientos de Futaleufú, Palena, Lago Verde, Río Ibáñez, Chile Chico, Lago O 'Higgins, entre otros (imagen 3). Así nace otra Patagonia, la 'Patagonia de Aysén', en la zona austral de Chile.

En aquella definición de Patagonianación, en el caso de Argentina, ella fue un espacio amplio y pampeano. En Chile, en cambio, fue cordillera, humedad y bosques impenetrables. Sin embargo, como el término Patagonia fue asumiendo la imagen de una pampa infinita, ella dio pasó a un perfil que se hizo muy común con el tiempo, creándose otra interpretación de Patagonia, la Patagonia estanciera y ovejera: "En poco más del medio siglo que se comenzó a tener interés en ella -escribía un visitante hacia 1930- la Patagonia ha llegado a ser la segunda después de Australia en crianza ovina. Las estancias salpican toda la Patagonia conocida" (Childs 1997: 260). Tal fue la fuerza de esta definición vocacional de aquellos lejanos territorios, que en la Patagonia de Chile, en la llamada región de Trapananda, luego Aysén, el Estado nacional fomentó una ocupación vía sociedades estancieras, cuyo fracaso colaboró a consolidar, hacia la década de 1940, la inmigración espontánea de colonos, especialmente de aquellos provenientes de la isla de Chiloé, Los Lagos y Araucanía. Esta Patagonia de colonos es aún una de las más arraigadas en el horizonte paisajístico de la nación chilena. En cierto modo, remite a una geohistoria cuya memoria dialoga con una historia ambiental donde la relación del hombre con el territorio es codificada a través de los roces o grandes quemas de bosques y la configuración de una identidad ganadera que perdura hasta el día de hoy. Aquella huella del vínculo ineludible del sujeto con el territorio que (lo) habita es también el sueño de la voluntad: “Esta colonización transformará los campos inhabitados en centros de población, a los desiertos inesplorados los llenará de grandes haciendas... la colonización ganadera despierta todos los espíritus!" (colono Antolín Silva, 1916, en Millar, 1990). 


\section{CONCLUSIONES.}

La geografía patagónica es, entonces, experiencia, pero en un sentido ontológico: "En la experiencia geográfica uno se abandona a la distracción, a la pluralidad de los detalles; otro concentra su interés en una forma dominante que estructura una realidad geográfica" (Dardel 2013: 97) ¿Qué es, entonces, Patagonia? volvemos a preguntar. De acuerdo a la hipótesis desarrollada aquí, es despliegue, es una posibilidad y un horizonte de sentido finito, móvil, en tránsito, que de tanto en tanto se constituye en mito. Como plantea Todorov (2013), la memoria es olvido y, tal vez por lo mismo, requiere de arquitecturas sociales que la definan, que le den un significado, un sentido. El sentido de quemar el bosque para alcanzar la civilización, el significado de conservar los bosques para llegar al desarrollo.

De este modo, una renovada manera de enfocar el 'problema geográfico', supondrá considerar la experiencia (temporalidad) o historicidad del espacio como soporte esencial de la interpretación que el sujeto social hace de él. En otras palabras, la interrogación del espacio implicará tener en consideración tanto la perspectiva comprensiva del sujeto como, a su vez, "la situación hermenéutica a la que pertenece" (Gadamer 1999: 477) aquella comprensión. Así, Patagonia no es Patagonia, es Patagonias, en plural. Es, en el fondo, una actualización renovada de significados geográficos que despliegan mitos, deslizan nuevas interpretaciones y un remozado horizonte del mundo. $\mathbf{\Delta} \boldsymbol{0}$

\section{REFERENCIAS}

Aliste, A. y Núñez. A, 2015. "Las fronteras del discurso geográfico: el tiempo y el espacio en la investigación social." Chungará, 47, (42), 287-301.

Arenas, F. Salazar, A. y Núñez, A. 2011. El aislamiento geográfico: problema u oportunidad. Experiencias, interpretaciones y politicas públicas. Santiago de Chile: Geo-libros.

Bachelard, G., 2010. La poética del espacio. México: FCE.

Bhabha, H., 1994. The location of culture. Londres: Routledge.

Biblioteca Nacional. Colección permanente Biblioteca Nacional (id MC: MC0018361 / id BN: 391157).

Canaparo, C., 2011. El imaginario Patagonia. Ensayo acerca de la concepción conceptual del espacio. Suiza: Peter Lang

Childs, H., 1997. El Jimmy, bandido de la Patagonia. Punta Arenas: U. de Magallanes.

Conservación Patagónica., s/f. Creating the future Patagonia National Park. Disponible en: www.

conservacionpatagonica.org

Dardel, E., 2013. Hombre y La Tierra. La Naturaleza de la realidad geográfica. Madrid: Biblioteca Nueva Dixie. F. 1996. A través de la Patagonia Punta Arenas. U de Magallanes.

Foucault, M., 2010. Las heterotopías. Buenos Aires: Nueva Visión.

Gadamer, H. G., 1999. Verdad y Método. Barcelona: Sigueme.

Harvey, D., 2007. Espacios del capital. Hacia una geografía crítica. Madrid: Aka.

Hegel, G. W. F., 1982. Lecciones sobre la filosofia de la Historia Universal. Madrid: Alianza

Heidegger, M., 1997. Ser y tiempo. Santiago de Chile: Universitaria.

Lindón, A. y Hiernaux, D. (Eds.), 2010. Los giros de la Geografía Humana. Desafíos y horizontes. México: UAMAnthropos.

Lois, C., 1999. "La invención del desierto chaqueño. Una aproximación a las formas de apropiación simbólica de los territorios del Chaco en los tiempos de formación y consolidación del Estado-Nación argentino."
Scripta Nova, 38, 1-12.

Mignolo, W. (Comp.), 2014. Capitalismo y geopolitica del conocimiento. Buenos Aires: Signo

Muñoz. M. D. 2009. Transformaciones urbanas de las ciudades chilenas de/ siglo XVIII Tesis doctoral. Madrid U. Politécnica de Madrid

Nogué, J., 2009. La construcción social del paisaje. Madrid: Biblioteca Nueva.

Núñez A., Aliste, E. y Bello, A.. 2014. "El discurso del desarrollo en Patagonia-Aysén: la conservación y la protección de la naturaleza como dispositivos de una renovada colonización. Chile, siglos XX-XXI." Scriota Nova, 18, (493), 1-13

Núñez, A., 2013. "Geografía, historicidad y hermenéutica." Revista de Geografía Norte Grande, 54, 257-268 Pigafetta. A. 1999 El primer viaje alrededor del mundo Relato de la expedición de Magallanes y Elcano. Barcelona: Ediciones B.

Real Academia Española, 2012، "Patagonia." En Diccionario de la Lengua Española (20e edición). Madrid: Espasa.

Ritchie Key, M. 2002 "El significado de Patagonia." Estudios Filológicos, 37, 261-266.

Rojas, M., 1992. América Imaginaria. Barcelona: Lumen.

Said, E., 2002. Orientalismo. Barcelona: Editorial Debate.

Soja. E, 1996 . Thirdspace Journeys to Los Angeles and other real-and-imagined places. Cambridge: Mass. Blackwel.

Todorov, T., 2013. Los usos de la memoria. Santiago de Chile: Signos.

Tuan, Y., 2007. Topofilia: Un Estudio de las Percepciones, Actitudes y Valores sobre el Entorno. Madrid: Melusina

Zusman, P., Haesbaert, H., Castro, H. y Adamo, S. (Eds.), 2011. Geografias Culturales: aproximaciones intersecciones y desafíos. Buenos Aires: UBA 